\title{
Simulation Study of a Stand-alone Wind-Pumped Storage System
}

\author{
Hao Guo ${ }^{a}$, Zheng $\mathrm{Li}^{\mathrm{b}}$ \\ College of Information Science and Technology, Donghua University, Shanghai China, 201620 \\ aguohaogoodluck@163.com, ${ }^{b}$ lizheng@dhu.edu.cn
}

\begin{abstract}
In order to improve the penetration of wind energy in a grid, pumped storage system for smoothing the fluctuations of wind power has been presented. A stand-alone wind-pumped storage and hydropower system which can transform wind power into conventional hydropower integrating to the grid can maximize wind energy penetration. In this case, operation control and stable of the stand-alone wind-pumped storage system is one of key technologies. In this paper, the configuration of a stand-alone pump-storage system only consisting of wind turbine and pumps is proposed. Simulation results shown that the system can operate stably.
\end{abstract}

Keywords- stand-alone system; pumped-storage; wind energy

\section{INTRODUCTION}

In order to improve the penetration of wind energy, energy storage systems are used to smoothing the fluctuations of wind power. In which, wind-pumped storage system is an option [1][2]. Wind-pumped storage system can function as peak clipping, valley filling of the power demand of a grid [2] and can also used to reduce the variability of the wind energy[3][4].

For an isolated grid, if its wind energy penetration has reached to limitation, the power that can integrate into the grid further should be steady and could be dispatch. In [5], a scheme of wind-pumped storage and hydropower system is presented, shown in Fig.1. The fluctuating wind energy is converted to potential energy of water by wind-pumped storage at first and then a constant power energy generated by hydro generator is injected into grid. Paper [5] only gives out the system allocation and steady state research results. In this paper control strategy of the pumps is discussed. And the method for balancing the energy of the stand-alone system under fluctuating wind energy is presented.

\section{SYSTEM DESCRIPTION}

hydropower plant when connected to the grid. The system schematic is shown in Fig.2. Where the type of wind turbines is wind turbine with permanent magnet synchronous generator. The pumps are Centrifugal pumps that can operate at variable speed. Every pump is driven by a squirrel cage induction machine, which is controlled by a variable frequency converter. Controller should adjust the speed of pumps and switch between the pump groups according to the wind power. A group of pumps consist of two pumps in parallel. Multiple groups of pumps may be electrically connected in parallel at the electric source. Efficiency of pumps is vital to the efficiency of whole pump-storage system. So, high efficiency is one of conditions for selecting pumps.

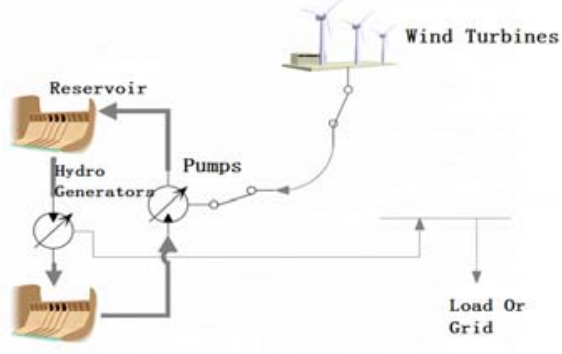

The stand-alone wind-pumped storage power station, shown in Fig.1, can transform the variable wind energy into the conventional hydroelectricity power, so as to increase the generation capacity of isolated grid with a stable power source.

Proper allocation (capacity ratio) of wind turbine, water pump, reservoir and hydroelectricity generator, and efficiency and economy of the system is one of issues for constructing the system. With reasonable configuration, wind-hydro-pumped storage station can serve not only as a peak regulator but also as a conventional power source. Paper [5] was presented the layout of wind-pumped energy storage system under the consideration of wind, rainfall data and the capacity of reservoirs and the control and dispatch of the wind-driven pumped storage

Figure 1. Schematic of wind-pumped storage system

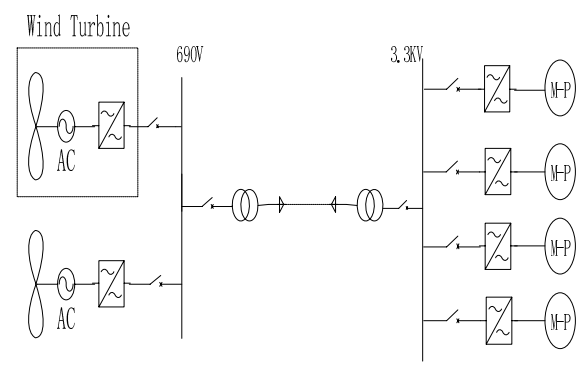

Figure 2. AC system schematic 


\section{SySTEM ALLOCATION AND CONTROL STRATEGY}

\section{A. Pumps allocation}

The capacity of wind turbine can be determined in terms of capacity of reservoirs, wind data and rainfall. For $10 \mathrm{MW}$ PTS system, we choose five $2 \mathrm{MW}$ variable-speed wind turbines with direct-drive permanent-magnet synchronous generator in study.

\section{B. Pumps control}

There are two operational modes for the control of pumps. The input power of pumps can cover the fluctuating range of wind power through switching between two modes over several groups of pumps.

For $10 \mathrm{MW}$ wind power, there are three types of pumps, 5 pumps totally. The switching boundaries are listed in Table1.

TABLE 1 SWITCHING BOUNDARIES OF OPERATIONAL MODES OF PUMPS

\begin{tabular}{|c|c|c|}
\hline No. & $\begin{array}{l}\text { Wind } \\
\text { Interval(MW) }\end{array}$ & Control Modes \\
\hline WPI 1 & $5 \sim 10$ & $\begin{array}{l}\text { Double 5MW pump: Op-Mode } \\
2\end{array}$ \\
\hline WPI 2 & $2.5 \sim 5$ & One 5MW pump: Op-Mode 1 \\
\hline WPI 3 & $1.25 \sim 2.5$ & $\begin{array}{l}\text { Double } 1.5 \mathrm{MW} \text { pump: } \\
\text { Op-Mode } 2\end{array}$ \\
\hline WPI 4 & $0.65 \sim 1.25$ & One 1.5 MW pump: Op-Mode \\
\hline WPI 5 & $0.3 \sim 0.65$ & $\begin{array}{l}\text { One } 0.65 \mathrm{MW} \text { pump: Op-Mode } \\
1\end{array}$ \\
\hline
\end{tabular}

\section{Simulation Result And AnAlysis}

A. Model of the wind turbines with permanent magnet synchronous generator

1) Model of turbine. The equations of turbine model are (1):

$$
\begin{gathered}
\left\{\begin{array}{l}
P=\frac{1}{2} \rho \pi R^{2} C_{P}(\lambda, \beta) v^{3} \\
\lambda=\frac{\omega_{t} R}{v} \\
C_{P}(\lambda, \beta)=0.22\left(\frac{116}{\lambda_{i}}-0.4 \beta-5\right) e^{-\frac{12.5}{\lambda_{i}}} \\
\frac{1}{\lambda_{i}}=\frac{1}{\lambda+0.08 \beta}-\frac{0.035}{\beta^{3}+1}
\end{array}\right. \\
\left\{\begin{array}{l}
2 H_{t} \cdot \frac{d \omega_{t}}{d t}=T_{t}-T_{m}-D_{t} \omega_{t} \\
2 H_{g} \cdot \frac{d \omega_{g}}{d t}=T_{m}-T_{e}-D_{g} \omega_{g} \\
T_{m}=D_{m}\left(\omega_{t}-\omega_{g}\right)+K_{m} \int\left(\omega_{t}-\omega_{g}\right) d t
\end{array}\right.
\end{gathered}
$$

In (1), $\mathrm{P}_{\text {is }}$ the captured mechanical power by turbine;

is air density; $\mathrm{R}$ is wind wheel radius; is tip-speed ratio, is pitch angle;.$t$ is wind wheel speed; $\mathrm{v}$ is wind speed; CP is power coefficient, as a function of pitch angle and tip-speed ratio

2) Model of transmission chain. Two mass model of the shafting is equation (2)

Where: $H_{t} 、 H_{g}$ are inertia time constant of turbine and generator, respectively; $t 、 g$ are speed of the turbine and generator rotor respectively; $D_{t} 、 D_{g}$ are own damping coefficient of the turbine and generator ,respectively; $D_{m}$ is mutual damping coefficient; $K_{m}$ is stiffness coefficient; $T_{t}$ is mechanical torque of wind turbine; $T_{e}$ is electromagnetic torque of the generator; $T_{m}$ is the mechanical torque of generator

3) Model of permanent magnet synchronous generator (PMSG). The equations of PMSG in the $\mathrm{d}-\mathrm{q}$ coordinate system are (3):

$$
\left\{\begin{array}{l}
v_{d s}=-R_{s} i_{d s}-\omega_{e} \psi_{q s}+\frac{d \psi_{d s}}{d t} \\
v_{q s}=-R_{s} i_{q s}-\omega_{e} \psi_{d s}+\frac{d \psi_{q s}}{d t} \\
\psi_{d s}=L_{d} i_{d s}+\psi_{f} \\
\psi_{q s}=L_{q} i_{q s} \\
T_{e}=\omega_{e} \psi_{f} i_{q s}-\omega_{e}\left(L_{d}-L_{q}\right) i_{d s} i_{q s}
\end{array}\right.
$$

Where: $R s$ is the stator resistance of the PMSG; $i_{d s}$, $i_{q s}, v_{d s}, v_{q s}, d_{d s},{ }_{q s}$ are the stator d-axis, q-axis current, voltage, flux, respectively; $e$ is the electrical angular frequency of the generator; $\quad f$ is the permanent magnet flux of the rotor; $L_{d}, L_{q}$ are the inductance of d-axis and q-axis of the stator, respectively.

4) Converter Model. The equations of converter model $\operatorname{are}(4)$.

$$
\left\{\begin{array}{l}
C u_{d c} \cdot \frac{d u_{d c}}{d t}=P_{s}-P_{g} \\
P_{s}=v_{d s} i_{d s}+v_{q s} i_{q s} \\
P_{g}=v_{d c} i_{d g}+v_{q c} i_{q g}
\end{array}\right.
$$

The loss of frequency can be ignored for it is very small, then the DC voltage are: where: $u_{d c}$ is DC voltage; $P_{s}, P_{g}$ are active power of inverter on side of generator and grid, respectively; $i_{d g} 、 i_{q g} 、 v_{d c} 、 v_{q c}$ are the current and voltage component on the $\mathrm{d}$-axis and $\mathrm{q}$-axis of converter on grid-side, respectively.

The voltage equation on $\mathrm{d}-\mathrm{q}$ coordinate system of converter on grid side:

$$
\left\{\begin{array}{l}
v_{d g}=v_{d c}+R i_{d g}+\omega_{e} L i_{q g}+L \frac{d i_{d g}}{d t} \\
v_{q g}=v_{q c}+R i_{q g}-\omega_{e} L i_{d g}+L \frac{d i_{q g}}{d t}
\end{array}\right.
$$

The working state means the transient state of the pump in an instantaneous. It is related to the flow Q, head $\mathrm{H}$, efficiency shaft power $\mathrm{P}$ and so on. Their relationship is shown above. The own characteristic curve of the 
pumps and the pipe's characteristic curves together determine the operating state of the pump.

\section{B. Pump model}

The pump-driver system can be modeled as follows:

$$
J \frac{d \omega_{r}}{d t}=T_{e}-T_{p}-k \omega_{r}
$$

Where, $J$ is the total inertia of the motor and the pump, $T e$ is the electromagnetic torque of the IM, $T_{p}$ the load torque acting on the IM, and $\mathrm{k}$ is the viscous factor. $T_{p}$ may be seen as a disturbance.

For synchronously variable-speed pumps, the total flow equals to the sum of each individual pump, while the head lifts are equal. That is

$$
\begin{aligned}
& H=a_{1} q_{1}^{2}+a_{2} q_{1} n+a_{3} n^{2} \\
& P_{\text {in }}=2 \frac{P_{s h}}{\eta_{m}}=2 \times \frac{b_{1} q_{1}^{3}+b_{2} q_{1}^{2} n+b_{3} q_{1} n^{2}+b_{4} n^{3}}{\eta_{m}} \\
& H_{c}=H_{\text {stat }}+k\left(q_{1}+q_{2}\right)^{2}
\end{aligned}
$$

The $n, H$ and $q_{i}$ obtained from above equations can then be used in simulation.

\section{Model of the pipe}

The characteristics of flow and head of pipe is given in (8). Slope of the curve depends on the material, the resistance coefficient $\mathrm{C}$, diameter and flow rate. Pipeline resistance coefficient $\mathrm{C}$ increases, the curve steepens.

$$
H_{c}=H_{\text {stat }}+C q_{v}^{2}
$$

Where $H_{\text {stat }}$ is the lifting height, i.e. static head, $q_{v}$ is the flow

\section{V.SIMULATION}

To validate the stability of stand-alone system and the operational principles proposed, the typical operation cases of the system has been simulated in Matlab.

As mentioned, the DDPMSG based wind turbine has the advantage of being capable of self-starting. This argument is validated by a simulation case, where the wind speed is set to grow from $3 \mathrm{~m} / \mathrm{s}$ to $6 \mathrm{~m} / \mathrm{s}$ in 4 seconds, and stays at $6 \mathrm{~m} / \mathrm{s}$. The wind speed waveform is given. It should be mentioned that during the simulation no special measures in hardware or control need to be taken for the successful self-starting.

Fig. 4to Fig. 8 show the waveforms of during the self-starting of the system.

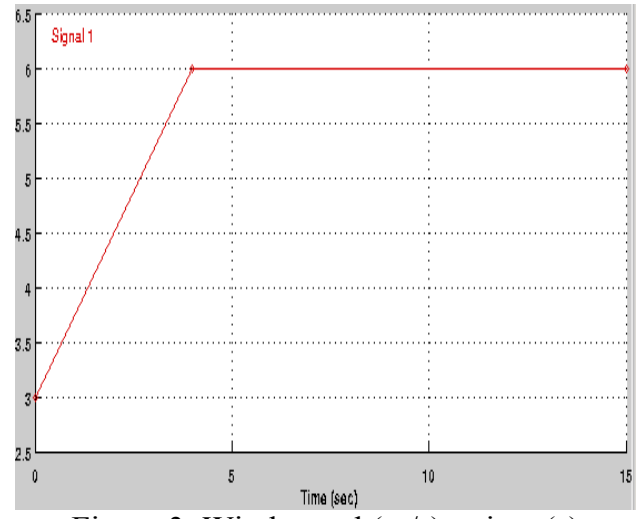

Figure 3. Wind speed $(\mathrm{m} / \mathrm{s})$ - time $(\mathrm{s})$

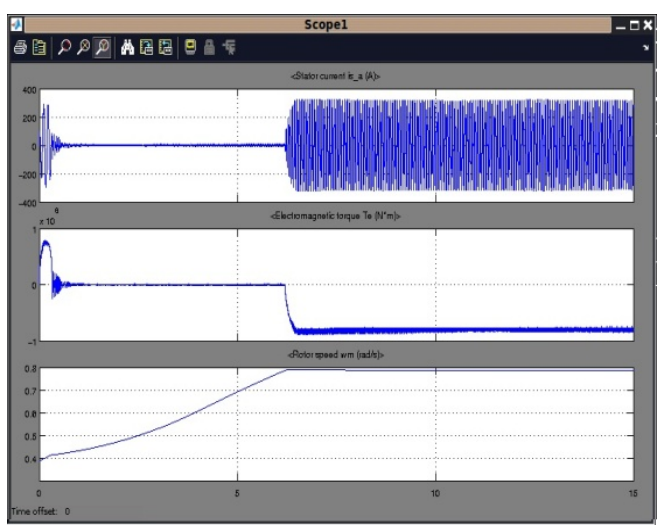

Figure 4. DDPMSG waveforms - time (s) Top: Stator phase A current (A), Middle: Electromagnetic torque $(\mathrm{Nm})$, Bottom: Rotor speed ( $\mathrm{rad} / \mathrm{s})$

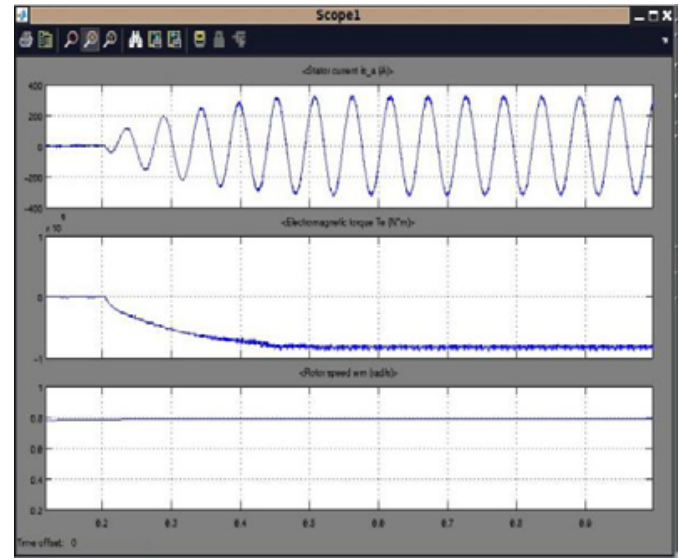

Figure 5. Zoomed waveforms of the Fig. 4 Top: Stator phase A current (A), Middle: Electromagnetic torque $(\mathrm{Nm})$, Bottom: Rotor speed ( $\mathrm{rad} / \mathrm{s})$ 


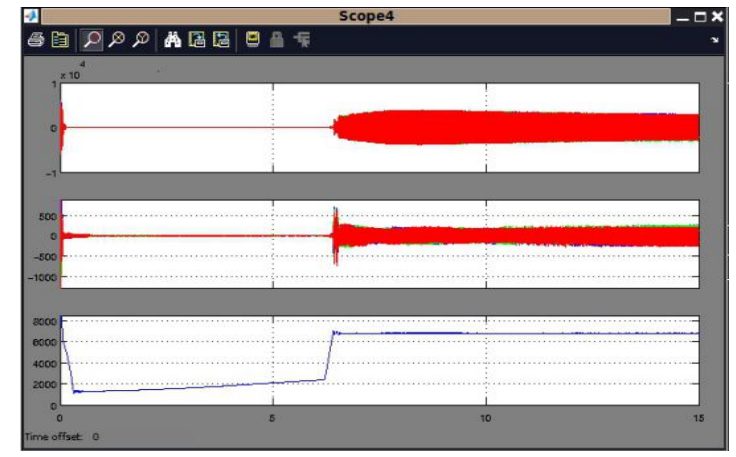

Figure 6. Power line and DC link voltage waveforms Top: Power line phase voltages (V); Middle: Power line phase currents (A), Bottom; DC link voltage of the wind turbine converter $(\mathrm{V})$

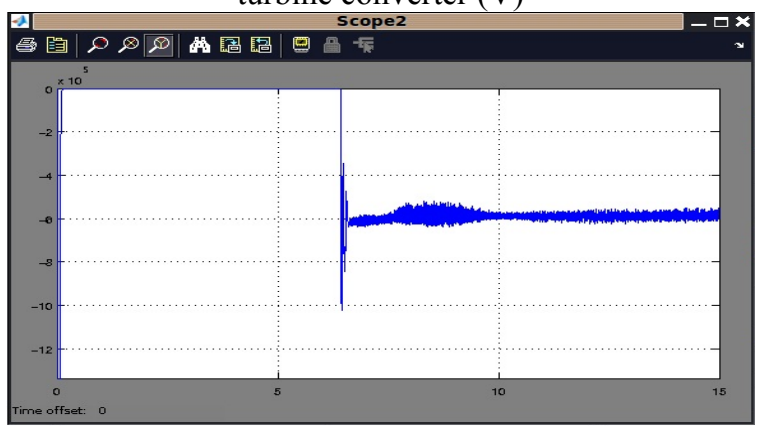

Figure 7. Transmitted power through the power lines (W) - time (s)

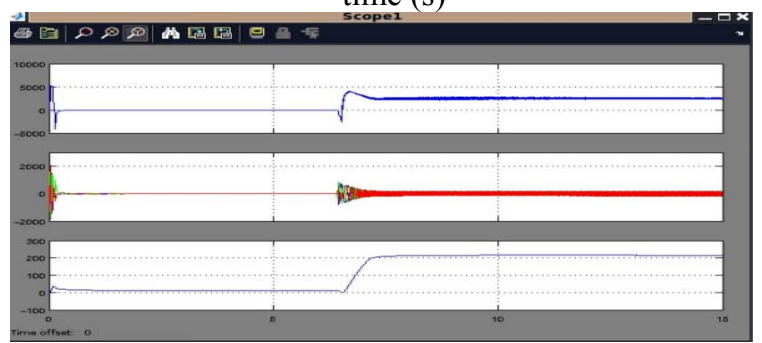

Figure 8. The SCIM waveforms - time (s)

Top: Electromagnetic torque (Nm), Middle: Stator currents (A), Bottom: Rotor speed ( $\mathrm{rad} / \mathrm{s})$
These waveforms have shown that the DDPMSG based wind turbine, together with the SCIM based pump, can self-start nicely and successfully.

\section{CONCLUSIONS}

Using pumped storage system in a power system is one of ways to raise the wind energy penetration on Islands. Furthermore, wind energy penetration can be maximized if wind-hydro-pumped storage station can generate power energy like a conventional generation unit. The challenge giving rise to from such a system is the stability of a stand-alone system consisting of wind turbines and pumps. The configuration of a stand-alone wind-pumped energy storage system is discussed in this paper. The stability and control strategy of the system is analyzed through simulation study. The operation power of pumps system can cover the fluctuation range of wind energy with high system efficiency. The simulation shows the system can stable operation.

\section{ACKNOWLEDGMENT}

The research is supported by the Shanghai Natural Science Foundation (No.14ZR1400700)

\section{REFERENCES}

[1] H. Ibrahim, A. Ilinca, J. Perron, "Energy storage systems-Characteristics and comparisons," Renewable and Sustainable Energy Reviews, 12 (2008) 1221-1250.

[2] S. V. Papaefthymiou, E. G. Karamanou, S. A. Papathanassiou and M. P. Papadopoulos, "A Wind-Hydro-Pumped Storage Station Leading to High RES Penetration in the Autonomous Island System of Ikaria," IEEE Xplore, 2010.

[3] H. Binder and T. Cronin, "Integration of wind power on the Faeroe Island," Risø National Laboratory for Sustainable Energy, February 2009.

[4] J. S. Anagnostopoulos and D. E. Papantonis, "Pumping station design for a pumped-storage wind-hydro power plant," Energy Conversion and Management, Vol. 48, No. 11, November 2007.

[5] Qian kun,Jiang yuxiang,Lizheng, Improve Wind Energy Penetration in an Isolated Power System by a Stand-alone Wind Pumped Storage Hydropower Plant, RESETE 2011,IEEE,2011.6 